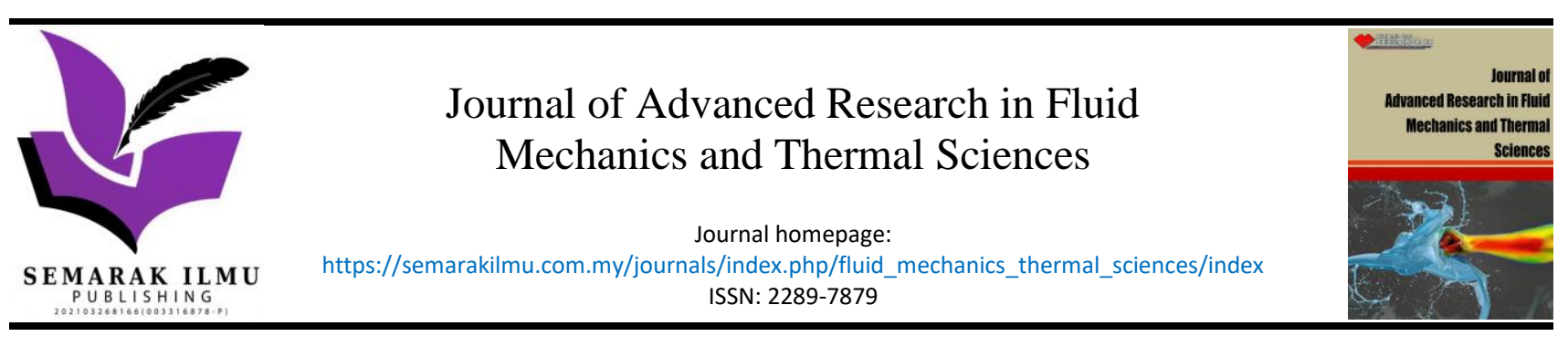

\title{
The Optimum Thickness of Rockwool as Roof Thermal Insulation: An Experimental and Numerical Study
}

\author{
Mohammed W. Muhieldeen ${ }^{1,3,}{ }^{*}$, Lim Chong Lye ${ }^{2, *}$, Mohammed Sameer Sharaf Kassim ${ }^{1}$, Wah Yen \\ Tey $^{1}$, Kah Hou Teng ${ }^{1,3}$ \\ Mechanical Engineering Department, Faculty of Engineering, Technology \& Built Environment, UCSI University, Cheras, Malaysia \\ School of Engineering and Technology, PSB Academy, Singapore \\ UCSI-Cheras Low Carbon Innovation Hub Research Consortium, Kuala Lumpur, Malaysia
}

\section{$\begin{array}{ll}\text { ARTICLE INFO ABSTRACT } & \end{array}$}

\section{Article history:}

Received 9 July 2021

Received in revised form 28 September 2021

Accepted 9 October 2021

Available online 19 November 2021

\section{Keywords:}

Saving Energy; Rockwool Insulation; Optimum Thickness; tropical climate; CFD

\begin{abstract}
Now a days, the global warming has increased the temperature in the environment that forced the building occupant to get assisting from the air condition to reduce the heat tension inside the building, this could increase the electricity bill amount. The aim of this study is to measure the optimum thickness of Rockwool insulation to experimentally and numerically to reduce the heating load inside the buildings. Two devices have been used through this research, Infrared Thermometer to measure profile temperature of the walls along with VELOCICALC to measure the air temperature and air velocity. Three different layers of Rockwool insulation have been applied on the roof of wooden room. The data present the two layers thickness of Rockwool is the best selection to reduce the heating load inside the room, the differential between outside and inside is $0.9^{\circ} \mathrm{C}$, the Rockwool of one layer reduced only $0.5^{\circ} \mathrm{C}$ and the maximum thickness with three layers reduced only $1{ }^{\circ} \mathrm{C}$, which is not much effective compared to the two layers but even more costly. CFD analysis shows agreement with the experimental result. The results shows if the dimensions of a UCSI lecture room is to be considered, then applying Rockwool insulation with a thickness of $100 \mathrm{~mm}$ would cost around RM 1520 as a UCSI lecture room is of $8 \mathrm{~m}$ width and $9 \mathrm{~m}$ length. However, two layers of Rock wool insulation could save around $29.30 \%$ of ROI per annum.
\end{abstract}

\section{Introduction}

Energy is a major global issue because it has a direct impact on the environment and economic development. Since conventional fuels are scarce, conserving energy is an essential consideration. Malaysia is located near the equator, which means it is hot and humid most of the time, with a high average temperature Lim et al., [1]. This led to the high usages of the air conditioning system to reduce the room temperature to comfort level. According to the study done by Kaynakli [2], the

\footnotetext{
* Corresponding author.

E-mail address: al-gailani@ucsiuniversity.edu.my

* Corresponding author.

E-mail address: chonglye.lim@psb-acdemy.edu.sg
}

https://doi.org/10.37934/arfmts.89.1.7791 
energy used for space heating and cooling accounts for about $60 \%$ of the total energy used in buildings in many countries, accounting for the largest proportion of energy consumption and accounting for approximately $40 \%$ of global energy demands.

The key principle of thermal insulation materials has been to reduce heat transfer from/to surfaces for a long time. An experimental study was done by Muhieldeen et al., [3] in Malaysia showed the efficiency of Polyethylene Aluminum Single Bubble (PASB) as an insulator and achieved a $2.7{ }^{\circ} \mathrm{C}$ reduction. The majority of the study conducted by several authors is based on building insulation for heating and cooling as well as the thermal comfort inside the buildings [3-10]. Although the study conducted by Bahadori and Vuthaluru [11], Öztürk et al., [12], Alawadhi [13], Chou [14], Kalyon and Sahin [15], Keçebaş et al., [16], Wechsatol et al., [17], Zaki and Al-Turki [18], Kayfeci [19], Muhieldeen et al., [20], and Muhieldeen et al., [21] is concentrating on pipeline insulation due to the significant potential for energy savings. Though, the insulator with uniform thickness was used for most of the mentioned studies. Recent questions about energy conservation and knowledge of scarce energy supplies prompted Bolattürk [4] and Muhieldeen et al., [22] to revisit the issue of thermal insulation.

According to an experimental report on energy use, almost $20 \%$ of energy in buildings is lost due to inefficient energy management. As a consequence, it can be resurrected by revising building energy management [23]. Thermal insulation is a significant contributor and a clear practical and logical first step toward achieving energy efficiency of the envelope-load in buildings located in harsh climatic conditions. The proper use of thermal insulation helps to reduce the amount of air conditioning used as well as the annual energy cost, and it also helps to extend the period of thermal comfort [24]. Increases in insulator thickness have a beneficial effect on heating load rather than cooling load, according to Lianying et al., [25]. Asdrubali et al., [26] carried out a review of potential commercial insulation products in 2015. Several studies discussed about the flow energy in different applications using CFD analysis, based on Salman et al., [27], Francesca et al., [28], Ng et al., [29], Tey et al., [30].

The present paper aims to find the optimum thickness for the effective thermal reduction with Rockwool as a roof insulator and compare it to the mathematical model developed by Mahlia et al., [8]. Furthermore, the cost analysis to be conduct for the optimum thickness of the insulator and determine the energy saving.

\section{Methodology}

\subsection{Room Design}

A prototype of a wooden room model with a volume of $1 \mathrm{~m}^{3}$ was fabricated. The prototype has four walls and roof, while the floor has been left it open to allow for air ventilation. The prototype being elevated with a stand. The front wall has a small opening for the temperature probe to measure the inner wall temperature. Rockwool insulator of different thicknesses to be installed on the wooden room's roof. The temperature of the wooden room's walls and its interior have been recorded. The temperature data were analyzed to determine the ideal thickness. These temperature readings were also used as inputs for simulations with SolidWorks software. The Rockwool insulator is supplied in layers, each with a thickness of $50 \mathrm{~mm}$, as per industry requirements, and the layers would be put on the roof of the wooden room to assess the Rockwool's effect on the room's temperature. The wooden prototype for the current study was made out of Balsa wood. Table 1 are the specifications of the Balsa wood [31]. 
Table 1

Balsa wood specifications [31]

\begin{tabular}{lll}
\hline Property & Value & Units \\
\hline Thermal Conductivity & 0.050 & $\mathrm{~W} /(\mathrm{m} . \mathrm{K})$ \\
Specific heat & 1.420 & $\mathrm{~kJ} / \mathrm{kg} . \mathrm{K}$ \\
Density & 178 & $\mathrm{~kg} / \mathrm{m}^{3}$ \\
Elastic Modulus & 0.175 & $\mathrm{GPa}$ \\
Poisson ratio & 0.290 & - \\
\hline
\end{tabular}

As shown in Figure 1 below, the Rockwool has 6 layers per pack and each layer with $50 \mathrm{~mm}$ thickness. The dimension of each pack is $1.2 \mathrm{~m} \times 0.6 \mathrm{~m}$ as per industry standard. It could be then cut into the desired dimension as per the roof size. Extra caution is required when handling the Rockwool insulator as it is hazardous. Gloves and mask must be worn while handling the Rockwool insulator. The Rockwool's thermal properties for this study is in Table 2.

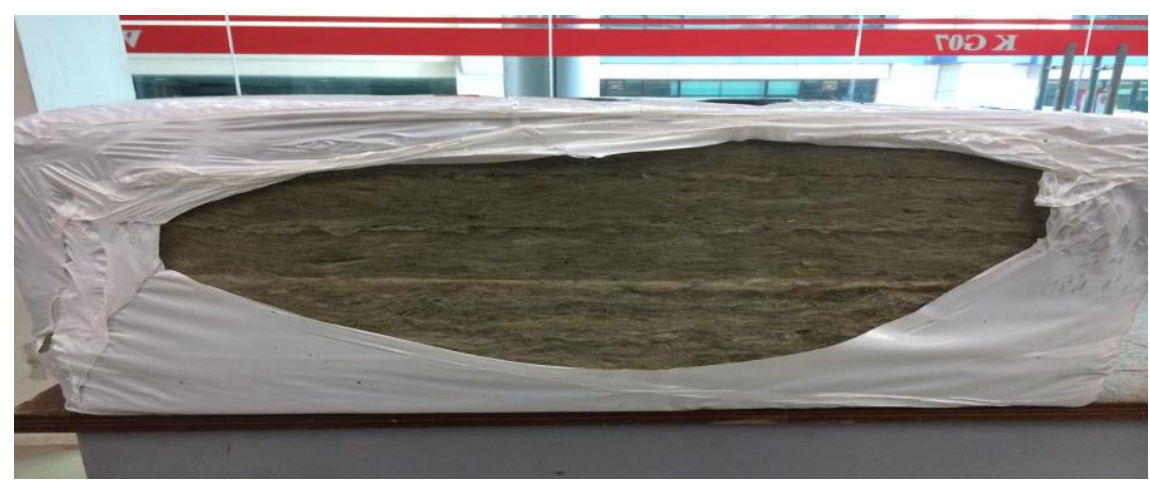

Fig. 1. Rockwool packed with 6 layers and thickness of $50 \mathrm{~mm}$ per layer

Table 2

Rockwool's thermal properties [32]

\begin{tabular}{ll}
\hline Specifications & Values \\
\hline Density $\left(\mathrm{kg} / \mathrm{m}^{3}\right)$ & 120.0 \\
$\mathrm{Cp}(\mathrm{J} / \mathrm{kg} . \mathrm{k})$ & 840.0 \\
Thermal Conductivity, $\mathrm{k}(\mathrm{w} / \mathrm{m} . \mathrm{k})$ & 0.045 \\
\hline
\end{tabular}

The total thermal energy conducted thru the wooden room via the insulated roof is the key values required for the aim of this project. The ambient temperature, air velocity, and temperature of the walls were all determined. The data of ambient temperature, air velocity, and temperature of the walls were recorded from 10 a.m. to 3 p.m. which the interval of the peak hours. The wooden room model was exposed to the sun for the majority of the day, with dimensions of $(1.2 \mathrm{~m}$ height $\times 0.9 \mathrm{~m}$ length $\times 0.9 \mathrm{~m}$ width) and the roof with Rockwool insulation as shown in Figure 2 . 


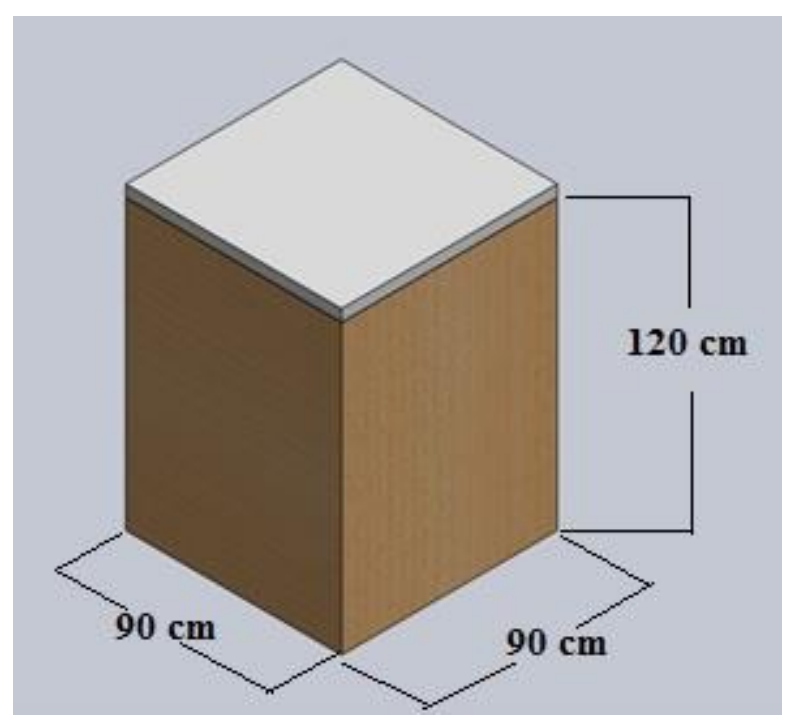

Fig. 2. Wooden room dimensions with on layer of Rockwool insulation

The measurement instruments used in this project are the TSI VELOCICALC multi-function ventilation meter and infrared thermometer. Figure 3 and Figure 4 show the TSI VELOCICALC meter and Infrared thermometer, respectively. These instruments deployed to measures the inner and outer air temperature, inner and outer air velocity of the wooden room model, between 10 a.m. to 3 p.m. The TSI VELOCICALC meter used to measures inner and outer air temperatures and inner and outer air velocity, while the infrared thermometer used to measure the temperature profile.

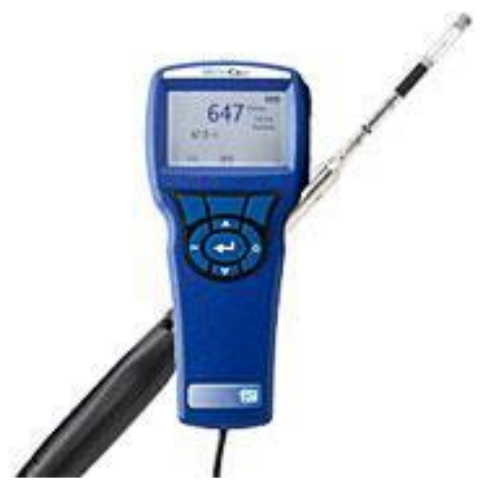

Fig. 3. TSI VELOCICALC Meter

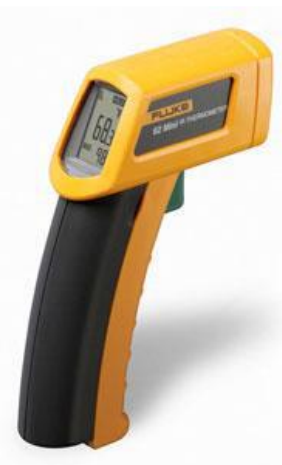

Fig. 4. Infrared Thermometer

\subsection{CFD Modelling}

ANSYS software have been used through to model and simulate the room. The room has meshed using Hex/Wedge, and the spacing was given as 0.07 as shown in Figure 5 . Therefore, defined the boundary condition of the walls, roof, and insulation as solid and room space as fluid. 


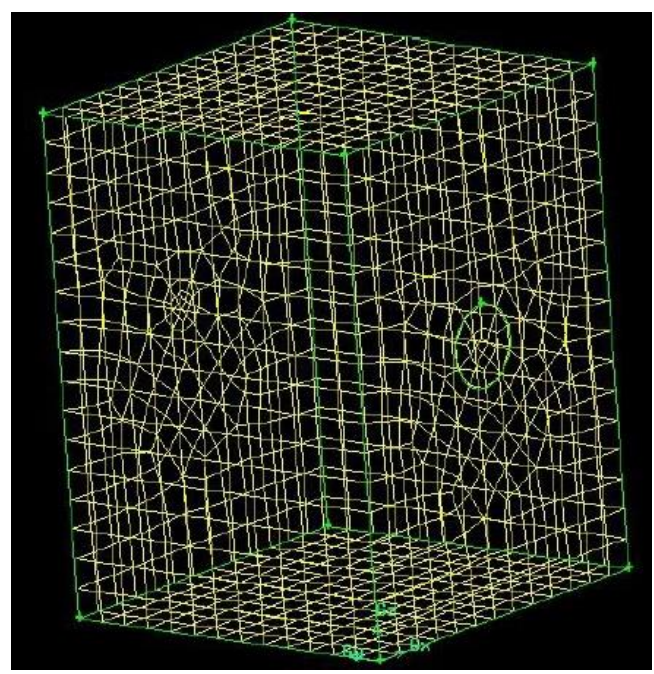

Fig. 5. Three dimensions view of mesh

ANSYS Fluent has been used to simulate the temperature distribution inside the room by applying all the data of the boundary condition. For the boundary conditions, the calculations for each heat flux have been calculated depending on the temperatures of the walls found in the experiment conducted on the prototype. Where the heat flux values of each wall as well as the thickness of the walls which remained $0.006 \mathrm{~m}$ except for the roof thickness that changed to $0.056 \mathrm{~m}$ due to the addition of the first Rockwool layer. Roof thickness changed to $0.106 \mathrm{~m}$ for the layer 2 test as the second Rockwool layer was added. And for the last test, the roof thickness was set to $0.156 \mathrm{~m}$ as the third and last Rockwool layer was placed on the top.

The controlling equations for this study are energy, three-dimensional 3D continuity and heat transfer equations of steady-state flow. These equations were used in the CFD program to compute the pressure drop and heat transfer, using finite volume methods and ANSYS Fluent. The first iteration starts with the initially stipulated solution and compares the results against the previous values to make a decision on the collection of values for the next iteration. This procedure is continued until a converged of the solution is declared. The solution arrives to convergence after approximately 700 iterations, as displayed in Figure 6.

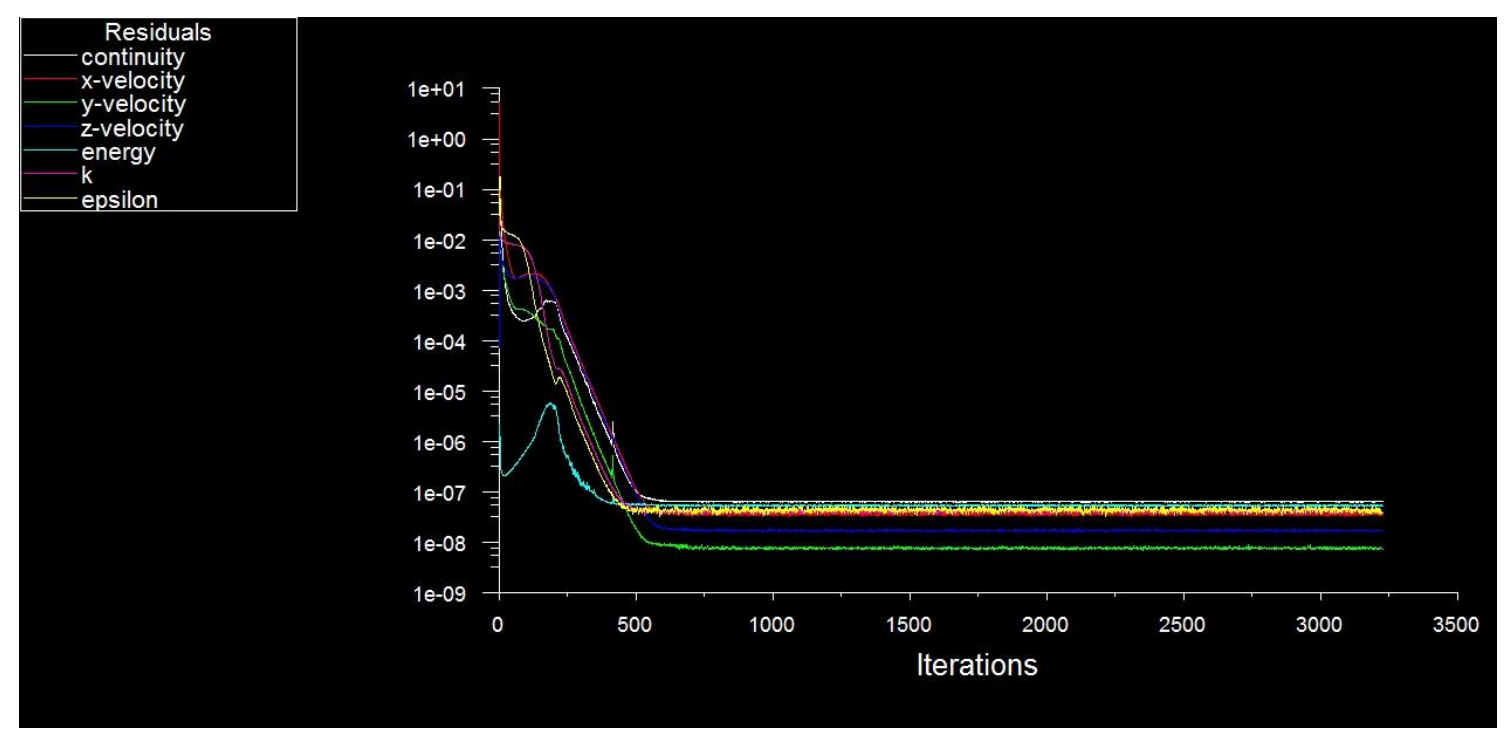

Fig. 6. Convergence history 


\section{Results and Discussion}

\subsection{Field Result}

This experiment aims to see how effective Rockwool insulation is at lowering building temperatures. A prototype of a wooden room model was built to accomplish this goal, with the measurements based on the size of the Rockwool insulator layer that would be applied to the roof. This experiment used three different Rockwool insulation thicknesses of $50 \mathrm{~mm}, 100 \mathrm{~mm}$, and 150 $\mathrm{mm}$, with experimental results obtained for both with and without Rockwool insulator. Air velocity, air temperature, and wall temperature were measured for a total of 20 days.

The temperature distribution results for case 1 to 3 which the roof with three different Rockwool insulation thicknesses of $50 \mathrm{~mm}, 100 \mathrm{~mm}$, and $150 \mathrm{~mm}$ presented in Figure 7 to Figure 9, respectively. The average inner and outer air temperature of the wooden room from the experiments for case 1 with one layer of Rockwool ( $50 \mathrm{~mm}$ thickness) has been recorded and plotted in Figure 7. As observed from Figure 7, the highest average temperature for the inner and outer room are $35.4{ }^{\circ} \mathrm{C}$ and $34.9^{\circ} \mathrm{C}$ at 1 p.m., respectively. This showed the effect of temperature decreased by $0.5^{\circ} \mathrm{C}$ for one layer of $50 \mathrm{~mm}$ Rockwool insulator.

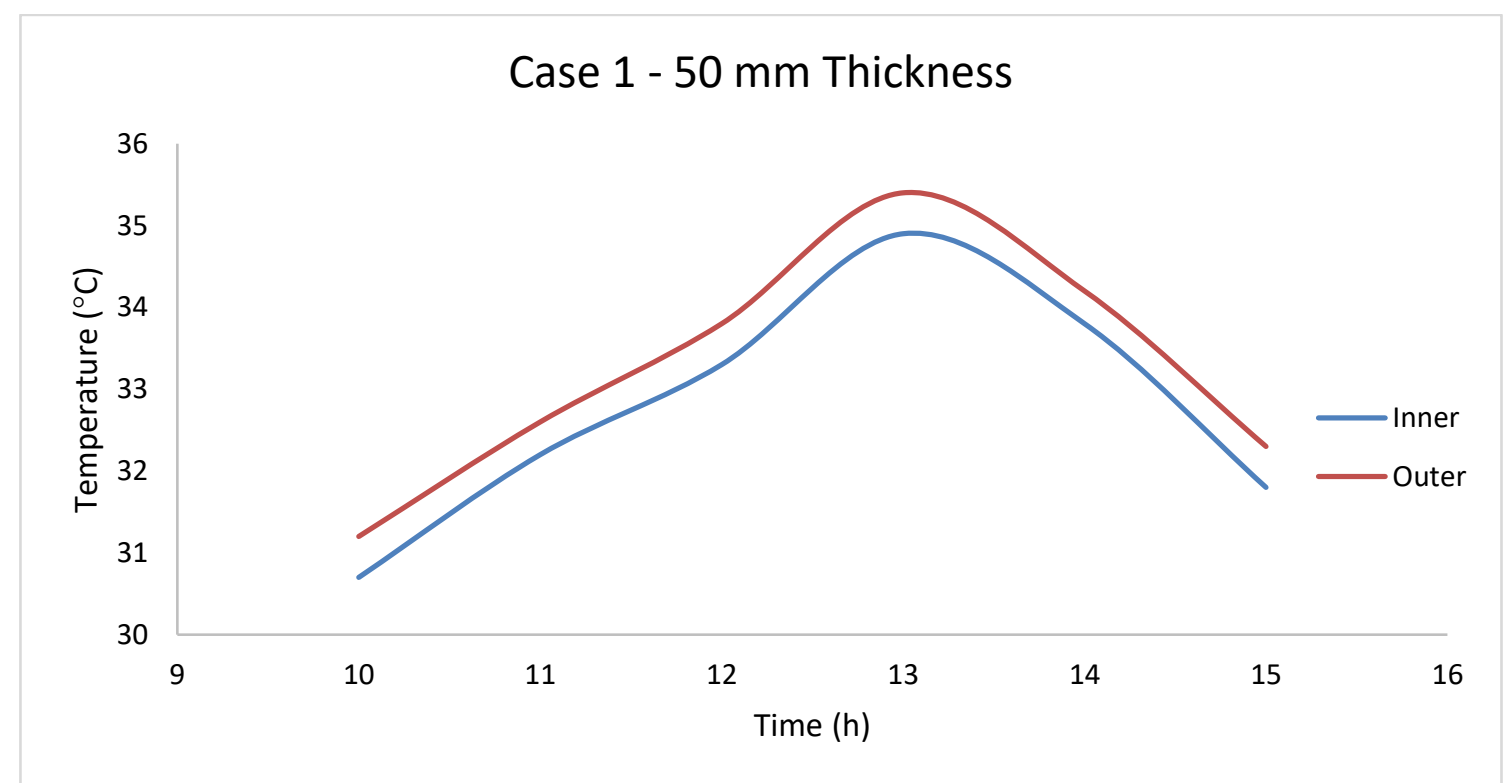

Fig. 7. Temperature Distribution Inside and Outside the Room with Single Layer of Rockwool Insulation

The average inner and outer air temperature of the wooden room from the experiments for case 2 with two layers of Rockwool (total of $100 \mathrm{~mm}$ thickness) has been recorded and plotted in Figure 8. As observed from Figure 8, the highest average temperature for the inner and outer room are 34.5 ${ }^{\circ} \mathrm{C}$ and $35.4{ }^{\circ} \mathrm{C}$ at 1 p.m., respectively. This showed the effect of temperature decreased by $0.9{ }^{\circ} \mathrm{C}$ for two layers of Rockwool insulator with a total $100 \mathrm{~mm}$ thickness. Also, it reveals that, two layers of Rockwool insulator provide $80 \%$ more effectiveness in term of temperature reduction as compared to one layer of Rockwool. 


\section{Case 2 - $100 \mathrm{~mm}$ thickness}

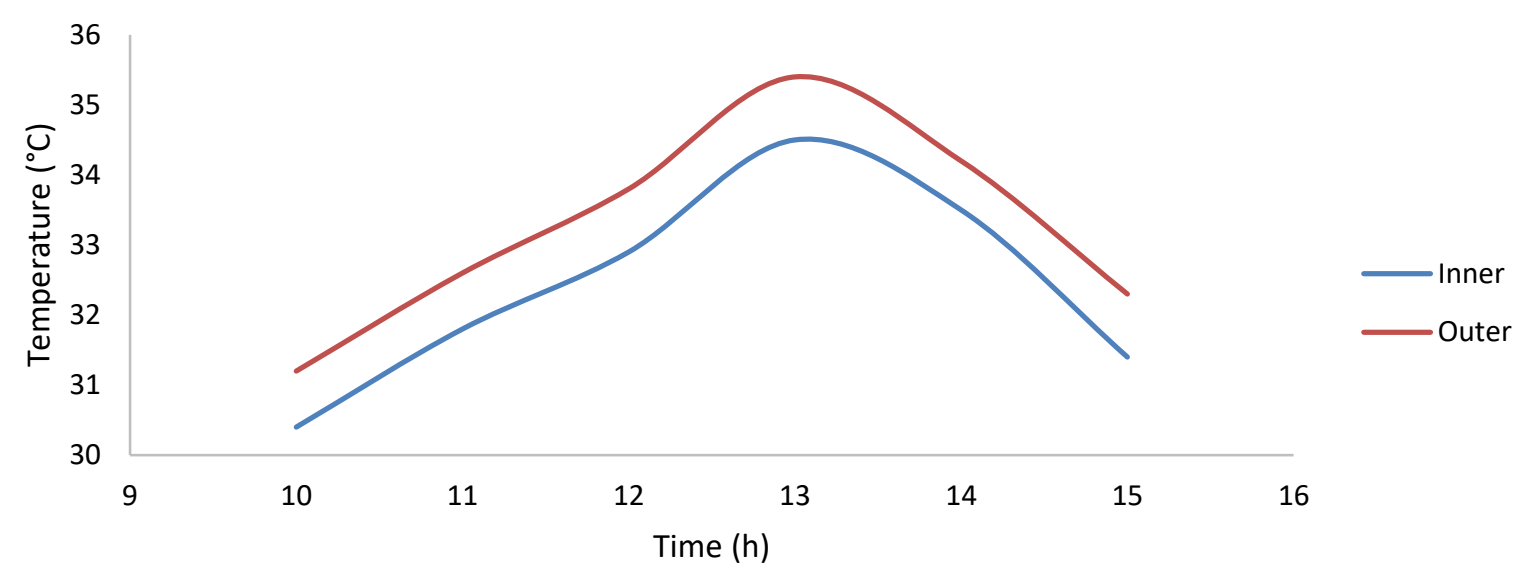

Fig. 8. Temperature Distribution Inside and Outside the Room with Two Layers of Rockwool Insulation

The average inner and outer air temperature of the wooden room from the experiments for case 3 with three layers of Rockwool (total of $150 \mathrm{~mm}$ thickness) has been recorded and plotted in Figure 9. As observed from Figure 9, the highest average temperature for the inner and outer room are 34.4 ${ }^{\circ} \mathrm{C}$ and $35.4{ }^{\circ} \mathrm{C}$ at 1 p.m., respectively. This showed the effect of temperature decreased by $1.0^{\circ} \mathrm{C}$ for three layers of Rockwool insulator with a total $150 \mathrm{~mm}$ thickness. If compared to case 2, it showed that three layers of Rockwool insulator provide $11 \%$ more effectiveness in term of temperature reduction as compared to two layers of Rockwool, which is a marginal improvement only.

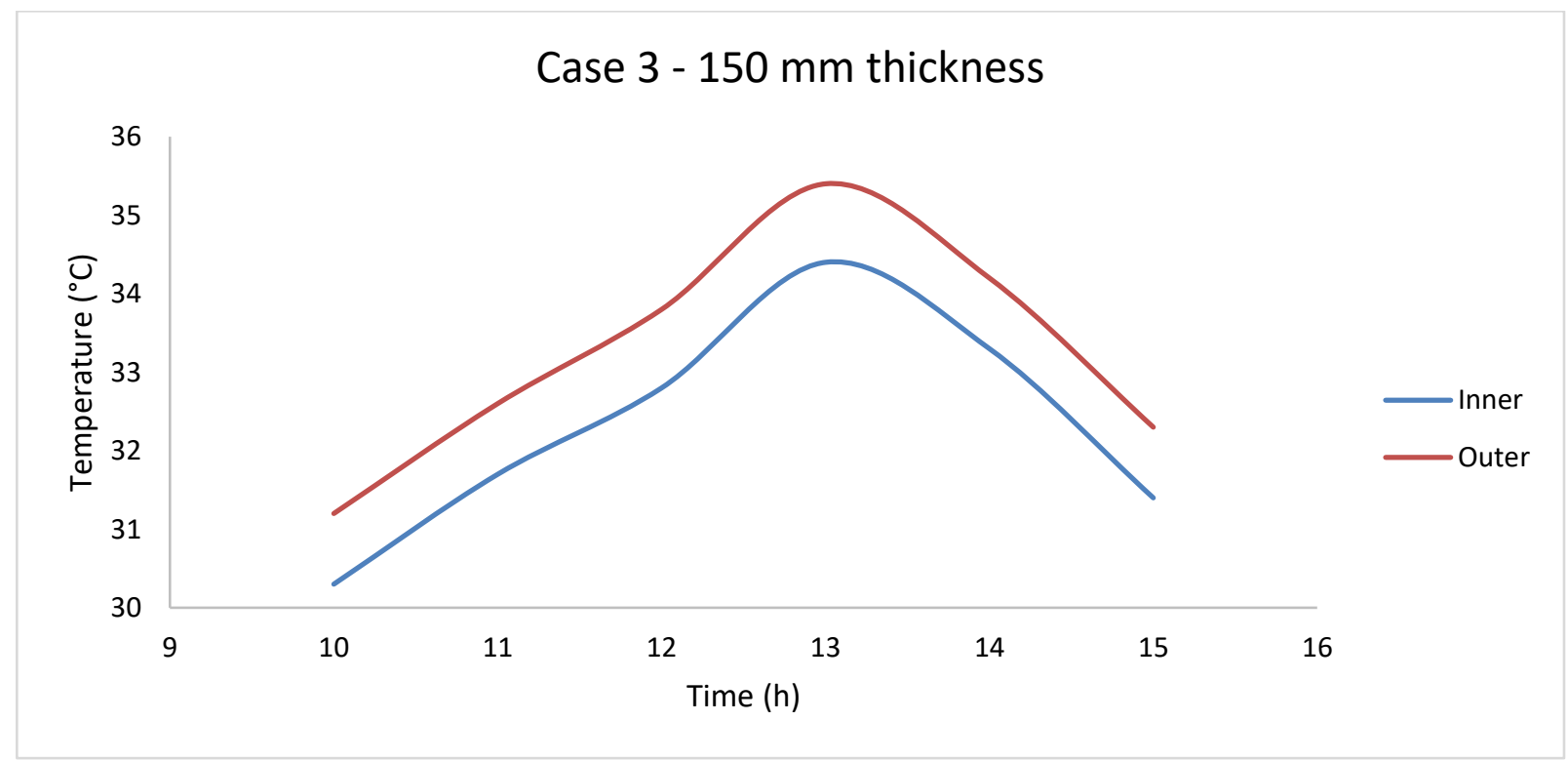

Fig. 9. Temperature Distribution Inside and Outside the Room with three layers of Rockwool Insulation

According to the findings, Rockwool insulation with a thickness of $100 \mathrm{~mm}$ had the best temperature control and cost savings, while the $50 \mathrm{~mm}$ thickness was inefficient, and the $150 \mathrm{~mm}$ thickness decreased the temperature marginally but not significantly compared to the $100 \mathrm{~mm}$ thickness layer while costing more, which was not worth it. 


\subsection{CFD Analysis}

\subsubsection{Simulation result without insulation}

The heat flux values that were inserted for the simulation results were obtained from the calculations in the experimental results. Figure 10 shows the temperature distribution along the walls of the room and the roof without applying any insulation layer. The area in dark blue resembles the lowest temperature along the walls while it increases as the areas goes from light blue to green. The lowest temperature which is at the bottom of the room is at $31.6^{\circ} \mathrm{C}$ while it increases up to $70{ }^{\circ} \mathrm{C}$ as it goes to the green area.

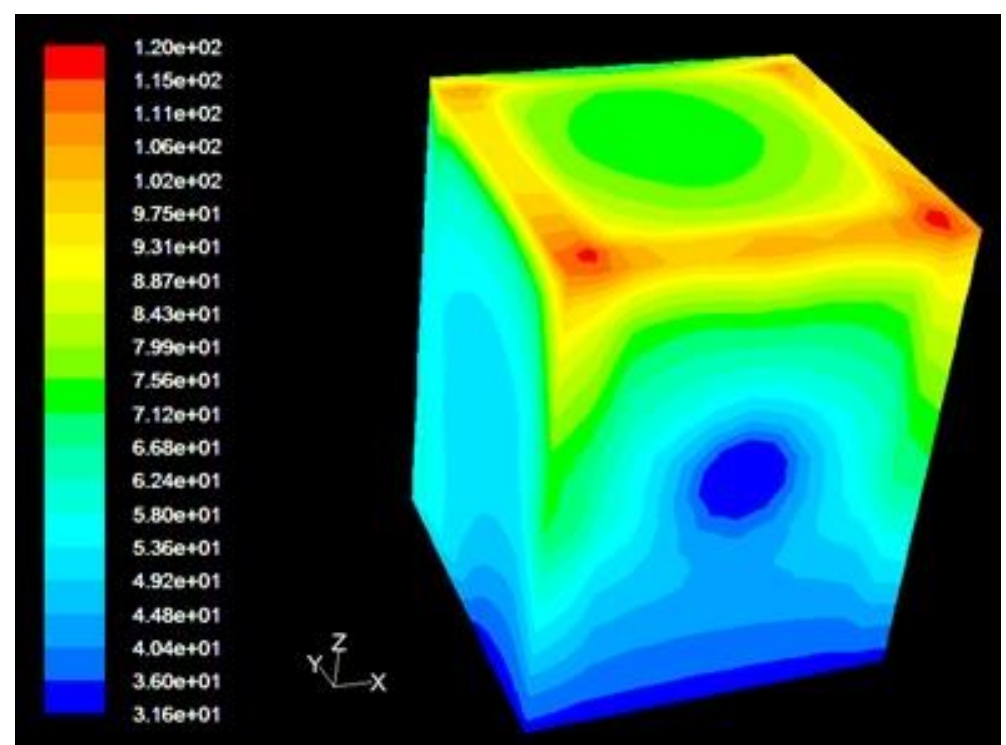

Fig. 10. Outer wall temperature distribution without insulation

While Figure 11 shows the temperature distribution in the inside of the room through the inner plane. The temperature inside is $31.6^{\circ} \mathrm{C}$ in almost the whole room except for a small area close to the roof where it goes to around $36^{\circ} \mathrm{C}$.

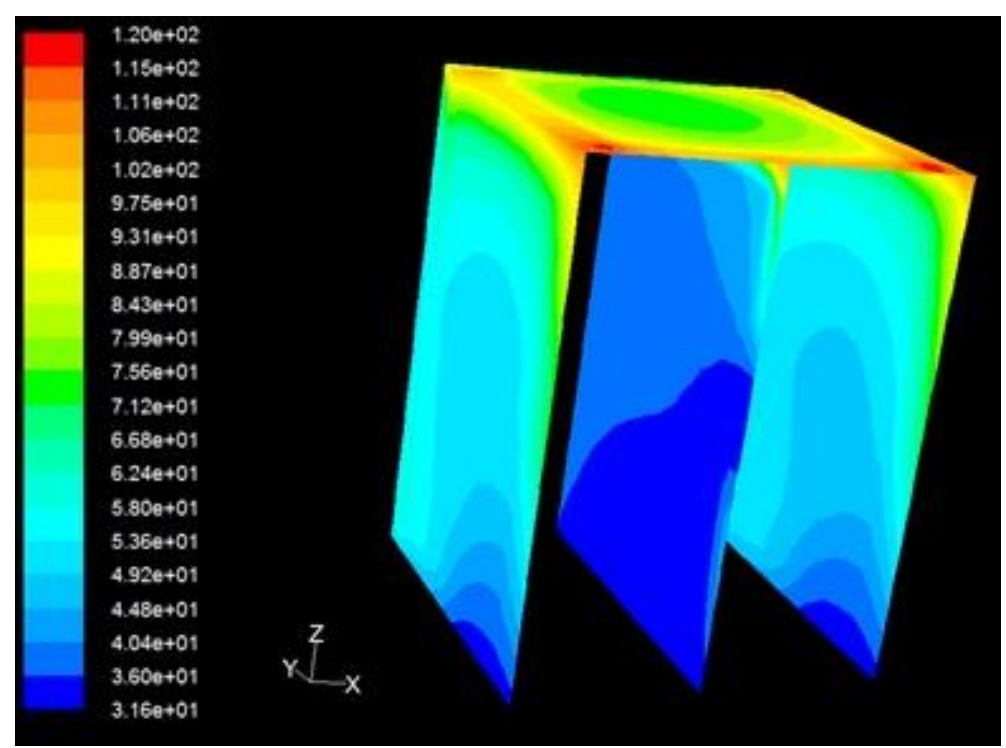

Fig. 11. Inner room temperature distribution without insulation 


\subsubsection{Simulation result with one layer of insulation}

Figure 12 shows the simulation results for the room after applying one layer of Rockwool. The figure shows that the temperature of the walls where the area is in dark blue is at $32.2^{\circ} \mathrm{C}$ where the outside temperature was $32.7^{\circ} \mathrm{C}$, and as the areas go from dark blue to light blue across the walls the temperature reaches up to $53{ }^{\circ} \mathrm{C}$ and that is only close to the roof. This mean that the one layer of Rockwool affected in increasing the dark blue area that represents the lowest temperature which is $32.2{ }^{\circ} \mathrm{C}$ as shown from the bottom of the room except for area close to the roof compared to the simulation results for the without insulation test that showed a small portion of the dark blue area from the bottom of the room.

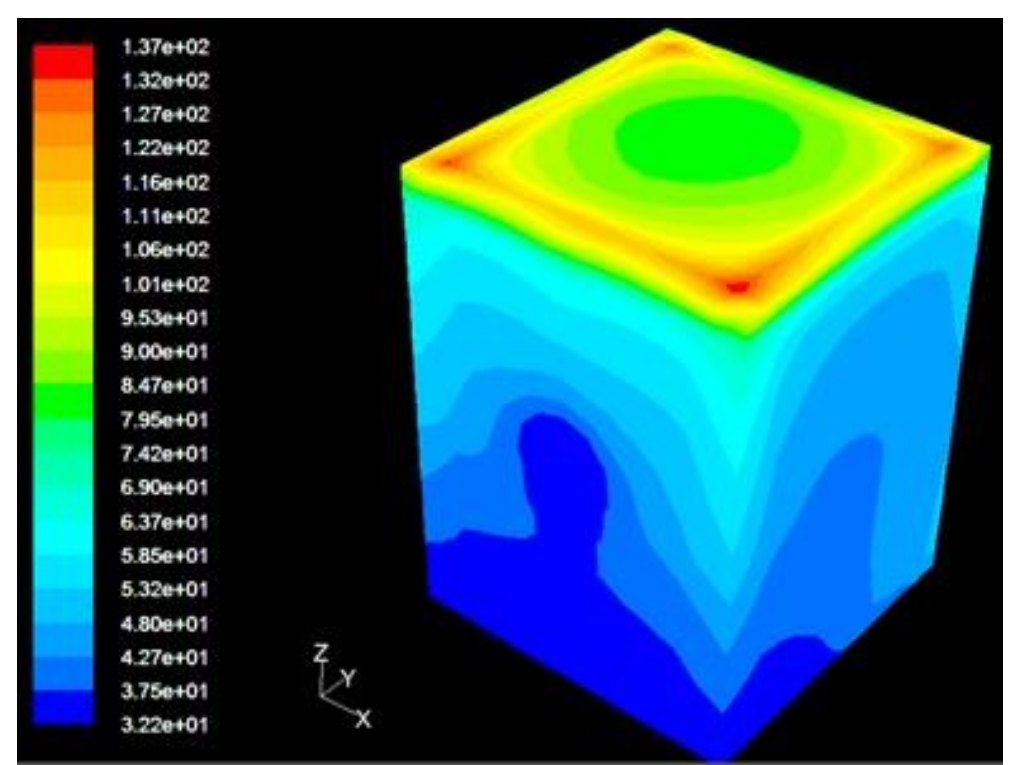

Fig. 12. Outer wall temperature distribution with one layer

Figure 13 shows the inner room temperature through the inner plane, and as it is shown the inner plane is mostly in dark blue colour which means that most of temperature inside the room is at 32.2 ${ }^{\circ} \mathrm{C}$ and as the area gets closer to the roof the temperature does not reach more than $37^{\circ} \mathrm{C}$ to take the fact that the room did not have any cooling system and was placed under the sun.

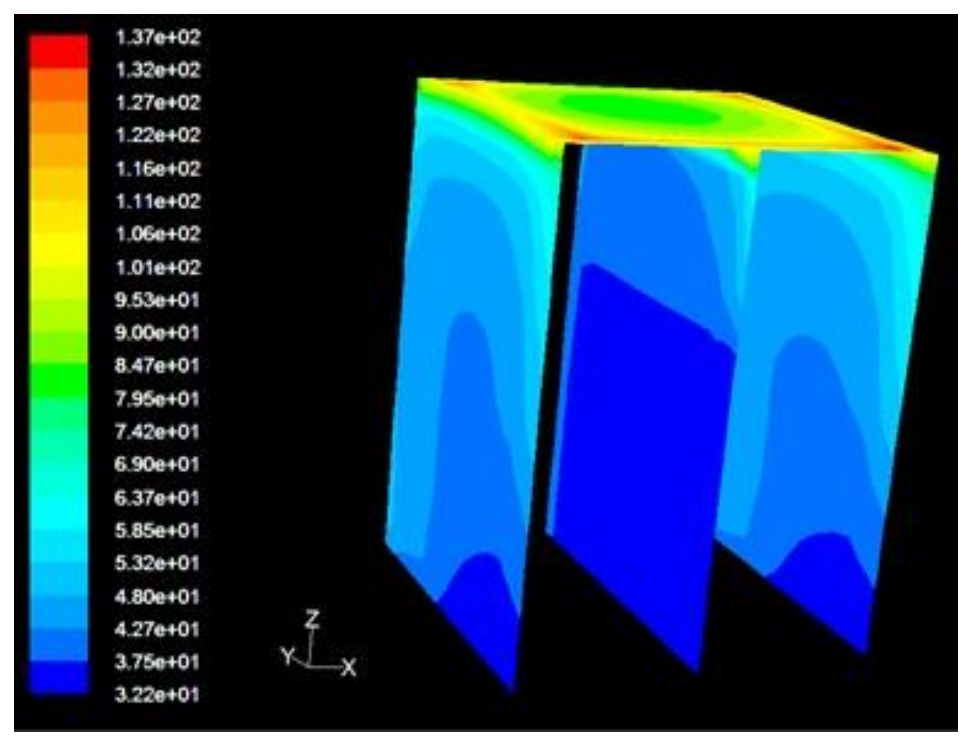

Fig. 13. Inner room temperature distribution with one layer 


\subsubsection{Simulation result with two layers of insulation}

Figure 14 shows the simulation results for the test conducted by applying the two layers of Rockwool insulation which gave a total of $100 \mathrm{~mm}$ thickness. The results show that the darker blue regions are increasing compared to the test that included applying only one Rockwool layer as the lowest temperature represented by the dark blue colour is $32.4^{\circ} \mathrm{C}$.

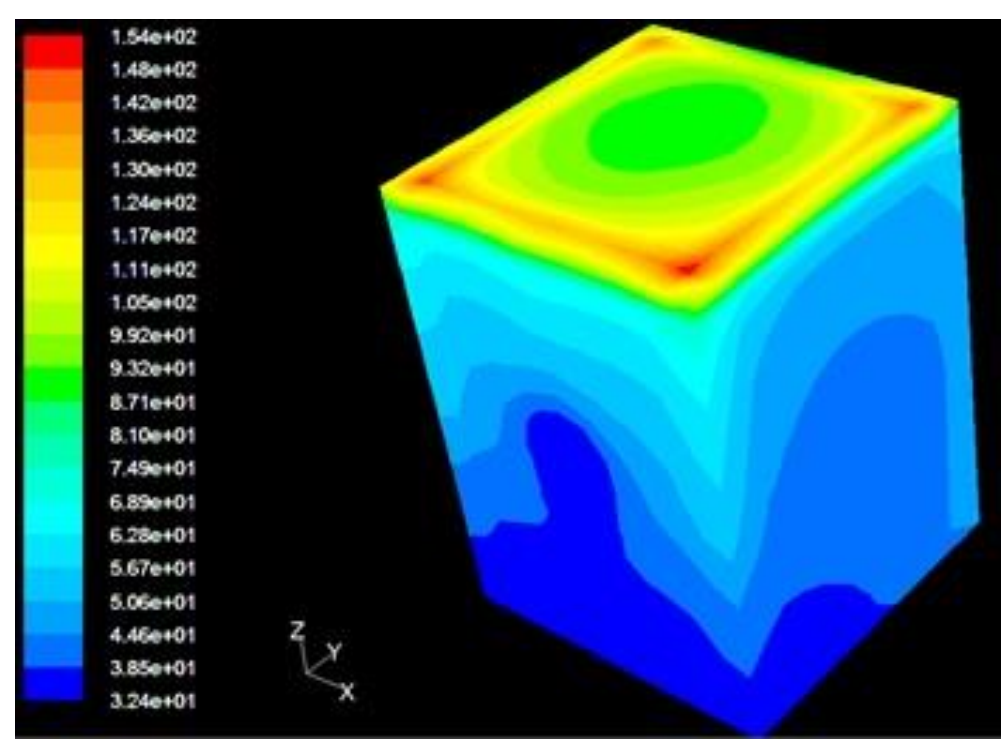

Fig. 14. Outer walls temperature distribution with two layers

Figure 15 shows the simulation results of the inner plane representing the inner room temperature where the temperature represented in dark blue is covering most of the plane with a temperature of $32.4^{\circ} \mathrm{C}$.

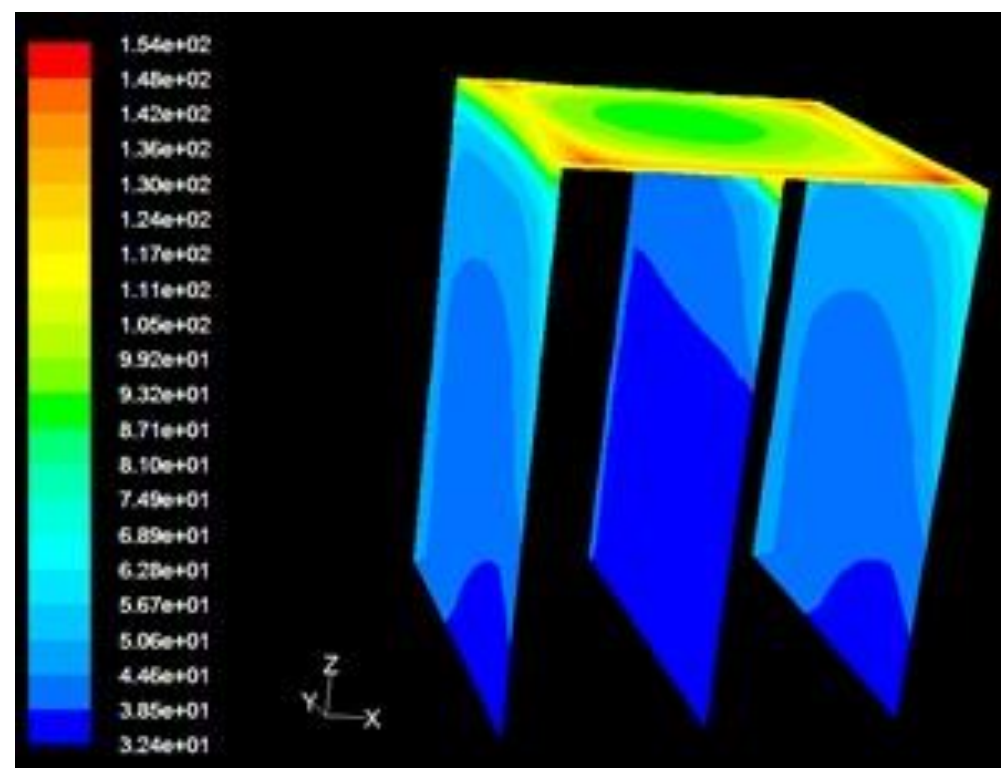

Fig. 15. Inner room temperature distribution with two layers 


\subsubsection{Simulation result with three layers of insulation}

Figure 16 shows the simulation results of the last test that included applying all 3 layers of Rockwool with a thickness of $150 \mathrm{~mm}$. The figure shows that the dark blue region that represents the lowest temperature which is at $32.6{ }^{\circ} \mathrm{C}$. The dark blue region is covering a wide range of the walls area compared to the test that included applying only one Rockwool layer but not a significant difference compared to the test that included applying two layers with $100 \mathrm{~mm}$ thickness.

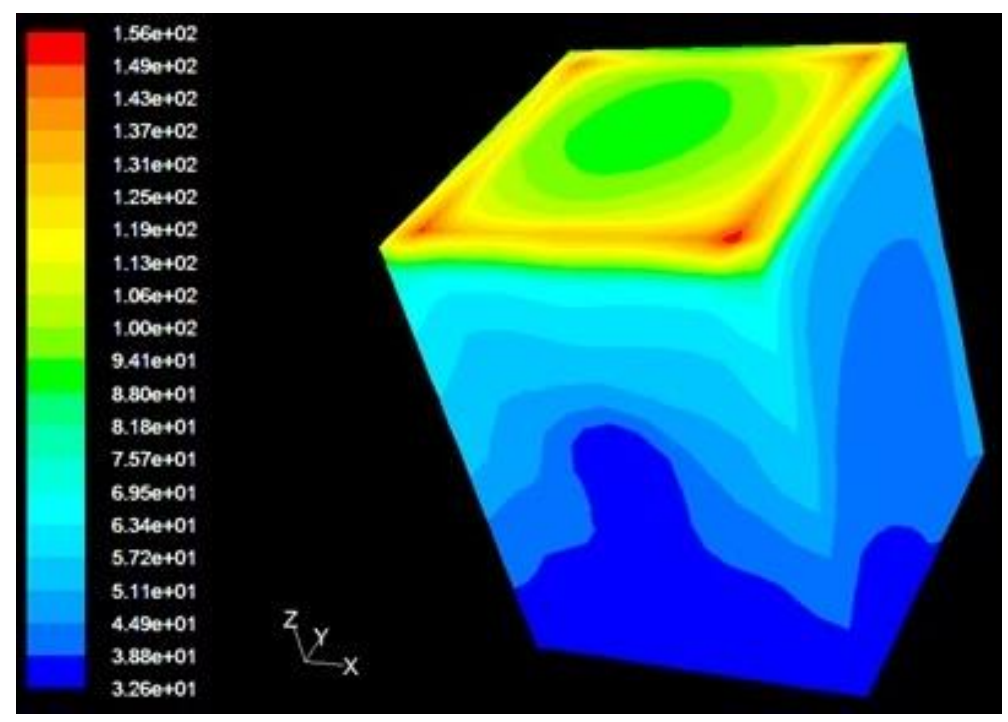

Fig. 16. Outer walls temperature distribution with 3 layers

While Figure 17 shows the inner room temperature across the inner plane, an as it is shown the temperature is at $34.6{ }^{\circ} \mathrm{C}$ as presented by the dark blue region across the plane in a wide range and the temperature increases a bit as it goes closer to the roof as shown by the light blue region.

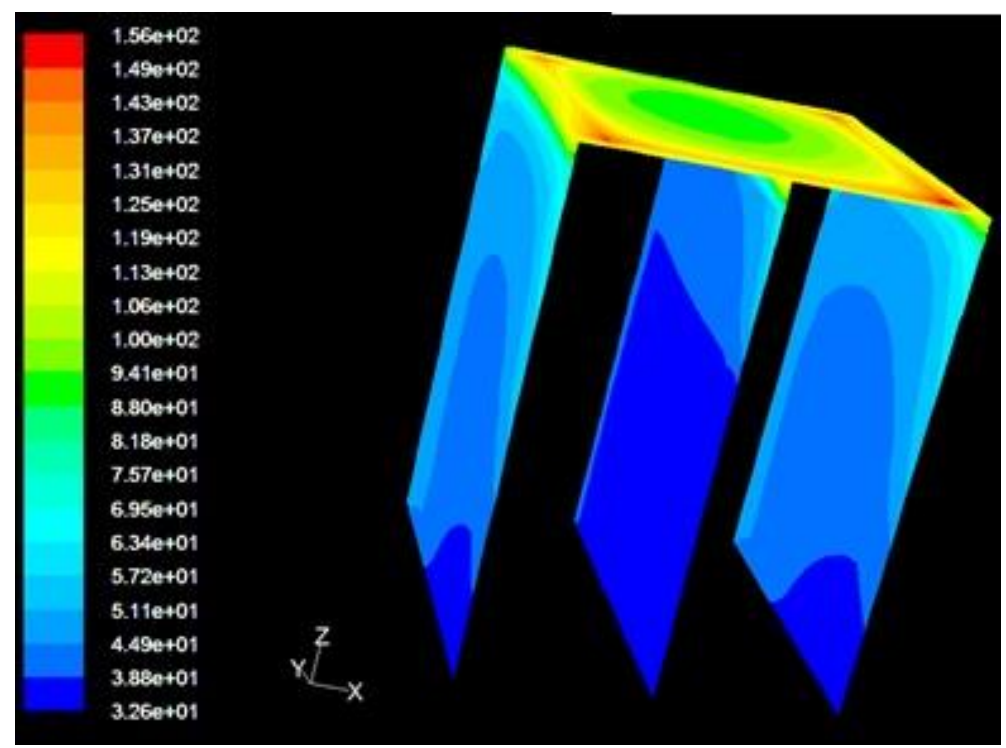

Fig. 17. Inner room temperature distribution with 3 layers 


\subsection{Experimental and Numerical Validation Results}

The validation between the numerical and experimental results is shown in Figure 18. The figure shows the temperature inside the room with insulation from the measured and simulated results and it also shows that the numerical results concur with the experimental ones. The error between the experimental measurements and the CFD result is very small, which is between $0.002 \%-0.0055 \%$.

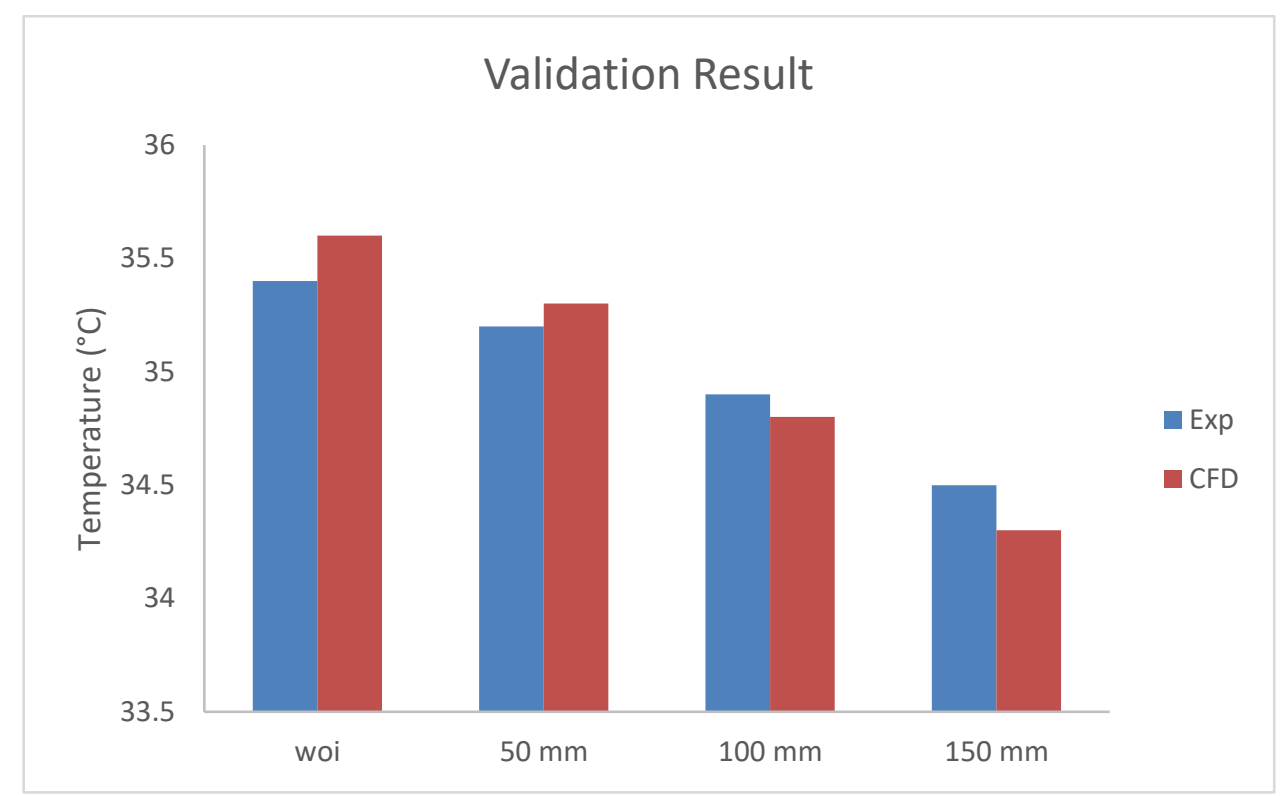

Fig. 18. Validation result between experimental and CFD result

\subsection{The Comparison Result of Different Thickness of Insulation}

According to the simulation results, applying two layers of Rockwool with a maximum thickness of $100 \mathrm{~mm}$ gives the best results in terms of lowering the inner room temperature and saving money, as it reduced the temperature by $2.31 \%$ compared to the test that included just one layer of Rockwool with a thickness of $50 \mathrm{~mm}$, which only reduced the temperature by $1.49 \%$.

A polynomial function based on Eq. (1) was provided to find the optimum thickness of insulating material in a study conducted by Mahlia et al., [8] on thicknesses of insulation materials.

$x_{o p t}=a+b k+c k^{2}$

where $a=0.0818, b=-2.973$, and $c=64.6 \& k=$ thermal conductivity of insulator.

Eq. (2) shown the calculation for the optimum thickness of the Rockwool insulator.

$x_{\text {opt }}=0.0818+(-2.973)(0.045)+(64.6)(0.045) 2(2)=0.078 \mathrm{~m}=78.8 \mathrm{~mm}$

This shows that Rockwool with total thickness of $100 \mathrm{~mm}$ is better than $50 \mathrm{~mm}$ and $150 \mathrm{~mm}$. Although the temperature reduction of $150 \mathrm{~mm}$ is marginally better than $100 \mathrm{~mm}$, but the cost of $100 \mathrm{~mm}$ is much more economic than $150 \mathrm{~mm}$. 


\subsection{Power Consumption Analysis}

Table 3 shows the monthly power consumption reduction for Rockwool insulation. The power consumption was calculated by assuming the air condition units operate for 10 hours a day and there is 30 days in a month. The results show that the application of Rockwool insulation with $150 \mathrm{~mm}$ gave the highest power consumption reduction followed by $100 \mathrm{~mm}$ and $50 \mathrm{~mm}$ as justified by the temperature reduction. However, as the calculation shows the $100 \mathrm{~mm}$ is efficient to be used in this study, therefore, two layers of insulation has been chosen in this analysis.

Table 3

\begin{tabular}{llll} 
Energy consumption & \multicolumn{3}{l}{} \\
\hline Method & $\begin{array}{l}\text { Monthly power } \\
\text { consumption (kWh) }\end{array}$ & $\begin{array}{l}\text { Monthly power } \\
\text { reduction (kWh) }\end{array}$ & $\begin{array}{l}\text { Percentage monthly } \\
\text { power reduction (\%) }\end{array}$ \\
\hline Without insulation & 432 & - & - \\
One layer & 360 & 71 & 19.7 \\
Two layers & 324 & 95 & 29.3 \\
Three layers & 305 & 102 & 33.4 \\
\hline
\end{tabular}

The electricity cost was calculated based on the electricity tariff by Tenaga Nasional Berhad. The first $200 \mathrm{kWh}$ was $21.80 \mathrm{cent} / \mathrm{kWh}$ per month, for the next $100 \mathrm{kWh}$ was $33.4 \mathrm{cent} / \mathrm{kWh}$ per month. The calculated electricity cost was tabulated in Table 4 of the real room. The results show that by applying Rockwool insulation with two layers could save the electricity cost the most while one layer insulation has the least electricity cost saved. This is due to $100 \mathrm{~mm}$ has the efficient power reduction comparing with other layers.

Table 4

Monthly electricity cost saving of the real room

\begin{tabular}{lllll}
\hline Method & $\begin{array}{l}\text { Monthly power } \\
\text { consumption (kWh) }\end{array}$ & $\begin{array}{l}\text { Monthly } \\
\text { Electricity cost } \\
(\mathrm{RM})\end{array}$ & $\begin{array}{l}\text { Monthly saving } \\
(\mathrm{RM})\end{array}$ & $\begin{array}{l}\text { Percentage monthly } \\
\text { saving (\%) }\end{array}$ \\
\hline Without insulation & 432 & 241.93 & - & - \\
One layer & 360 & 201.17 & 40.74 & 20.25 \\
Two layers & 324 & 186.43 & 54.27 & 29.17 \\
Three layers & 305 & 173.62 & 61.34 & 35.33 \\
\hline
\end{tabular}

\section{Conclusions}

The study's objective was to measure air temperature and air velocity inside an insulated room as input parameters for a CFD program. Three different layers of Rockwool insulation with three different thicknesses were applied on top of the roof of a prototype wooden room. Among the three different thicknesses we can conclude by the results given from ANSYS Fluent that the Rockwool layer with thickness $100 \mathrm{~mm}$ is more worthy of using than the $50 \mathrm{~mm}$ thickness layer or the $150 \mathrm{~mm}$ thickness layer. The objectives of this project were met, the student understands the use of CFD whether the use of ANSYS Fluent to model and analyse. The best results achieved from the thermal analysis for the Rockwool layer (100 mm thickness) was $0.9{ }^{\circ} \mathrm{C}$ difference between outside temperature and inner room temperature for an approximate cost of RM 19 compared to the results given by the Rockwool layer (50 mm thickness) which reduced $0.5^{\circ} \mathrm{C}$ for an approximate cost of RM 9.5 and to the Rockwool layer ( $150 \mathrm{~mm}$ thickness) which reduced $1{ }^{\circ} \mathrm{C}$ for an approximate cost of RM 8. Therefore, if the dimensions of a UCSI lecture room is to be considered, then applying Rockwool 
insulation with a thickness of $100 \mathrm{~mm}$ would cost around RM 1520 as a UCSI lecture room is of $8 \mathrm{~m}$ width and $9 \mathrm{~m}$ length. However, two layers of Rock wool insulation could save around $29.17 \%$ of ROI per annum.

\section{Acknowledgement}

This research was not funded by any grant.

\section{References}

[1] Lim, Chong Lye, Nor Mariah Adam, and Kamarul Arifin Ahmad. "Cryogenic pipe flow simulation for liquid nitrogen with vacuum insulated pipe (VIP) and Polyurethane (PU) foam insulation under steady-state conditions." Thermal Science and Engineering Progress 7 (2018): 302-310. https://doi.org/10.1016/i.tsep.2018.07.009

[2] Kaynakli, Omer. "A review of the economical and optimum thermal insulation thickness for building applications." Renewable and Sustainable Energy Reviews 16, no. 1 (2012): 415-425. https://doi.org/10.1016/i.rser.2011.08.006

[3] Muhieldeen, M. W., N. M. Adam, and B. H. Salman. "Experimental and numerical studies of reducing cooling load of lecture hall." Energy and Buildings 89 (2015): 163-169. https://doi.org/10.1016/j.enbuild.2014.12.026

[4] Bolattürk, Ali. "Optimum insulation thicknesses for building walls with respect to cooling and heating degree-hours in the warmest zone of Turkey." Building and Environment 43, no. 6 (2008): 1055-1064. https://doi.org/10.1016/j.buildenv.2007.02.014

[5] Muhieldeen, Mohammed W., Q. Y. Wong, Ummi Zulaikha Abd Rahman, and Wah Yen Tey. "Energy Saving by Applying Different Wall Thermal Insulations on a Room at Malaysian Institution." Journal of Advanced Research in Fluid Mechanics and Thermal Sciences 65, no. 1 (2020): 130-139.

[6] Kecebas, Ali, and Muhammet Kayveci. "Effect on optimum insulation thickness, cost and saving of storage design temperature in cold storage in Turkey." Energy Education Science and Technology Part A: Energy Science and Research 25, no. 1-2 (2010): 117-127.

[7] Muhieldeen, M. W., Y. R. Lim, Sunil Govinda, and Wah Yen Tey. "Investigation of the Effect of Awning using Sunlight Sensor to Reduce Cooling Load in the Room." Journal of Advanced Research in Fluid Mechanics and Thermal Sciences 67, no. 1 (2020): 136-145.

[8] Mahlia, T. M. I., B. N. Taufiq, and H. H. Masjuki. "Correlation between thermal conductivity and the thickness of selected insulation materials for building wall." Energy and Buildings 39, no. 2 (2007): 182-187. https://doi.org/10.1016/j.enbuild.2006.06.002

[9] Söylemez, M. S., and M. Ünsal. "Optimum insulation thickness for refrigeration applications." Energy Conversion and Management 40, no. 1 (1999): 13-21. https://doi.org/10.1016/S0196-8904(98)00125-3

[10] Muhieldeen, M. W., and Y. C. Kuang. "Saving Energy Costs by Combining Air-Conditioning and AirCirculation using CFD to Achieve Thermal Comfort in the Building." Journal of Advanced Research in Fluid Mechanics and Thermal Sciences 58, no. 1 (2019): 84-99.

[11] Bahadori, Alireza, and Hari B. Vuthaluru. "A simple correlation for estimation of economic thickness of thermal insulation for process piping and equipment." Applied Thermal Engineering 30, no. 2-3 (2010): $254-259$. https://doi.org/10.1016/i.applthermaleng.2009.08.010

[12] Öztürk, I. T., H. Karabay, and E. Bilgen. "Thermo-economic optimization of hot water piping systems: A comparison study." Energy 31, no. 12 (2006): 2094-2107. https://doi.org/10.1016/i.energy.2005.10.008

[13] Alawadhi, Esam M. "Thermal analysis of a pipe insulation with a phase change material: Material selection and sizing." Heat Transfer Engineering 29, no. 7 (2008): 624-631. https://doi.org/10.1080/01457630801922469

[14] Chou, Huann-Ming. "Optimum interior area thermal resistance model to analyze the heat transfer characteristics of an insulated pipe with arbitrary shape." Energy Conversion and Management 44, no. 18 (2003): 2915-2939. https://doi.org/10.1016/S0196-8904(03)00069-4

[15] Kalyon, Muammer, and Ahmet Z. Sahin. "Application of optimal control theory in pipe insulation." Numerical Heat Transfer: Part A: Applications 41, no. 4 (2002): 391-402. https://doi.org/10.1080/104077802317261236

[16] Keçebaş, Ali, Mehmet Ali Alkan, and Mustafa Bayhan. "Thermo-economic analysis of pipe insulation for district heating piping systems." Applied Thermal Engineering 31, no. 17-18 (2011): 3929-3937. https://doi.org/10.1016/i.applthermaleng.2011.07.042

[17] Wechsatol, W., S. Lorente, and A. Bejan. "Tree-shaped insulated designs for the uniform distribution of hot water over an area." International Journal of Heat and Mass Transfer 44, no. 16 (2001): 3111-3123. https://doi.org/10.1016/S0017-9310(00)00338-0

[18] Zaki, G. M., and A. M. Al-Turki. "Optimization of multilayer thermal insulation for pipelines." Heat Transfer Engineering 21, no. 4 (2000): 63-70. https://doi.org/10.1080/01457630050144514 
[19] Kayfeci, Muhammet. "Determination of energy saving and optimum insulation thicknesses of the heating piping systems for different insulation materials." Energy and Buildings 69 (2014): 278-284. https://doi.org/10.1016/j.enbuild.2013.11.017

[20] Muhieldeen, Mohammed W., Lim Zhen Yang, Lim Chong Lye, and Nor Mariah Adam. "Analysis of Optimum Thickness of Glass Wool Roof Thermal Insulation Performance." Journal of Advanced Research in Fluid Mechanics and Thermal Sciences 76, no. 3 (2020): 1-11. https://doi.org/10.37934/arfmts.76.3.111

[21] Muhieldeen, Mohammed W., Lim Chong Lye, M. S. S. Kassim, Tey Wah Yen, and K. H. Teng. "Effect of Rockwool Insulation on Room Temperature Distribution." Journal of Advanced Research in Experimental Fluid Mechanics and Heat Transfer 3, no. 1 (2021): 9-15.

[22] Muhieldeen, M. W., N. M. Adam, E. Salleh, S. H. Tang, and Q. J. Kwong. "Student behavior that leads to energy abuse at a teaching institution in Malaysia." In International Seminar in Sustainable Environment \& Architecture (9th SENVAR p2ND ISESEE 2008: Humanity and Technology), Uitm Shah Alam. 2008.

[23] Beggs, Clive. Energy: management, supply and conservation. Routledge, 2010. https://doi.org/10.4324/9780080942889

[24] Al-Homoud, Mohammad S. "Performance characteristics and practical applications of common building thermal insulation materials." Building and Environment 40, no. $3 \quad$ (2005): 353-366. https://doi.org/10.1016/i.buildenv.2004.05.013

[25] Lianying, Zhang, Wang Yuan, Zhang Jiyuan, Liu Xing, and Zhang Linhua. "Numerical Study of Effects of Wall's Insulation Thickness on Energy Performance for Different Climatic Regions of China." Energy Procedia 75 (2015): 1290-1298. https://doi.org/10.1016/j.egypro.2015.07.191

[26] Asdrubali, Francesco, Francesco D'Alessandro, and Samuele Schiavoni. "A review of unconventional sustainable building insulation materials." Sustainable Materials and Technologies 4 (2015): 1-17. https://doi.org/10.1016/i.susmat.2015.05.002

[27] Salman, B. H., M. Z. Hamzah, J. Purbolaksono, J. I. Inayat-Hussain, H. A. Mohammed, and M. W. Muhieldeen. "Determination of correlation functions of the oxide scale growth and the temperature increase." Engineering Failure Analysis 18, no. 8 (2011): 2260-2271. https://doi.org/10.1016/i.engfailanal.2011.08.001

[28] Francesca, Priscilla, Wah Yen Tey, Lit Ken Tan, and M. W. Muhieldeen. "Investigation on Generalised Trapezoidal Differencing Time-Marching Scheme for Modelling of Acoustical Wave." CFD Letters 12, no. 2 (2020): 11-21.

[29] Ng, Yu Han, Wah Yen Tey, Lit Ken Tan, Gerald Pacaba Arada, and M. W. Muhieldeen. "Numerical Examination on Two-Equations Turbulence Models for Flow Across NACA 0012 Airfoil with Different Angle of Attack." CFD Letters 12 , no. 2 (2020): 22-45.

[30] Tey, Wah Yen, Nor Azwadi Che Sidik, Yutaka Asako, Mohammed W. Muhieldeen, and Omid Afshar. "Moving least squares method and its improvement: A concise review." Journal of Applied and Computational Mechanics 7, no. 2 (2021): 883-889.

[31] Yu, Ziqing, and Aixi Zhou. "Fiber reinforced polymer composite structures in fire: modeling and validation." Mechanics of Advanced Materials and Structures 20, no. 5 (2013): $361-372$. https://doi.org/10.1080/15376494.2011.627639

[32] Jelle, Bjørn Petter. "Nano-based thermal insulation for energy-efficient buildings." In Start-Up Creation, pp. 129181. Woodhead Publishing, 2016. https://doi.org/10.1016/B978-0-08-100546-0.00008-X 